\title{
Assessment of Temporal Bone Diseases by High Resolution Computed Tomography - Institution based Study
}

\author{
Abhijit Kishorkumar Sankhla ${ }^{1}$, Neha Dubey ${ }^{2}$ \\ ${ }^{1}$ Senior Resident, Department of Radiodiagnosis, Ananta Institute of Medical Sciences, Udaipur, ${ }^{2}$ Senior Resident, Department \\ of Radiodiagnosis, Ananta Institute of Medical Sciences, Udaipur, India
}

Corresponding author: Abhijit Kishorkumar Sankhla, Senior Resident, Department of Radiodiagnosis, Ananta Institute of Medical Sciences, Udaipur, India

DOI: http://dx.doi.org/10.21276/ijcmsr.2019.4.2.20

How to cite this article: Abhijit Kishorkumar Sankhla, Neha Dubey. Assessment of temporal bone diseases by high resolution computed tomography - institution based study. International Journal of Contemporary Medicine Surgery and Radiology. 2019;4(2):B87-B90.

\section{A B S T R A C T}

Introduction: High definition computed tomography is a variation of routine Tomography. It gives a clean visual window of the temporal bone and enables minute structural of anatomy and physiology of temporal bone. The present study was conducted with the aim to assess the role of high resolution computed tomography in diseases of temporal bone and correlating the HRCT image findings with the pathological findings.

Material and Methods: The study was conducted amongst 100 patients who underwent HRCT temporal bone and relevant statistics are drawn from these cases. After local examination, clinical evaluation and consent, C.T scan was performed. Follow up of patients was done for confirmation with operative and/or histopathological findings whenever possible. The findings were noted in a tabulated form and a differential diagnosis were established.

Results: 61 cases were of infective etiology, out of which 16 were of chronic otomastoiditis, 4 were of chronic mastoiditis, 38 were of chronic otomastoiditis with cholesteatomas formation and 3 were of otitis externa. Out of 100 cases, 6 were of congenital pathology, 22 were of traumatic, 1 was of dysplasia, 4 were of neoplastic and 6 were normal. Among patients with structures involved due to cholesteatomas, facial nerve was involved in 26 cases, ossicles in 23 cases, tegmen tympaniin 19 cases, sinus plate in 21 cases, intracranial structures in 10 cases and inner ear in 12 cases.

Conclusion: Amongst patients with trauma to temporal bone, HRCT precisely predicts the fracture lines, disruptions of the ossicles and injury to facial nerve. Therefore, it enables the management of most of trauma subjects. A HRCT helps to explain the possible outcomes to the patient as well as assist the otologist to predict disease during the surgery

Keywords: High Resolution Computed Tomography, Mastoid, Temporal Bone, Radiology

\section{INTRODUCTION}

Earlier, in majority of the pathologies of temporal bone, diagnosis were established based on clinical evaluation alone. However, with elevation in the incidence of infective diseases of the ear, it was recommended that the present approach to prevent and treat the situation was not adequate. So, primarily in complicated and recurrent situations, imaging carries a crucial role, as imaging results may fundamentally affect the treatment. ${ }^{1}$

High definition computed tomography is a alteration of routine CT. It gives a direct visual window of the temporal bone and enables to visualize minute structural information of both anatomy and physiology of temporal bone. It has the advantage of providing outstanding topographic observations, devoid of superimposition from structures. It enables an accurate evaluation of pathology before surgical exploration with respect to the location, degree and complications of the disorder. ${ }^{2}$ In the developing nations like ours, this modality is easily available and inexpensive to the subjects. So, there are chances that the radiologist is likely experience greater frequency of HRCT studies and the knowledge of temporal bone on HRCT will be tremendously beneficial in achieving an accurate diagnosis. ${ }^{3}$ The present study was conducted with the aim to evaluate role of this imaging modality in temporal bone disorders and correlating the hrct image based results with both operative and pathological outcomes.

\section{MATERIAL AND METHODS}

It was a prospective study done in department of Radiodiagnosis and Imaging in Ananta Institute of Medical Science and Research Center Rajsamand, Rajasthan in collaboration with the deparment of otorhinolaryngology amongst patients with suspected temporal bone disorder. It was conducted for a period of 8 months from June 2018 to February 2019. The study is carried out on 100 patients who underwent HRCT temporal bone and relevant statistics are drawn from these cases. The subjects included were both male and females, in the age group of 1year to 60 year. The subjects referred from OPD or IPD with chief complaints and clinical outcomes relating to temporal bone disorder for examination by high resolution CT were enrolled in the study. Inclusion 
criteria was suspected unsafe chronic serous otitis media (CSOM), known or suspected deformities of inner, middle or external ear, suspected temporal bone fracture, suspected tumors of temporal bone evaluation of congenitally deaf child and evaluation of tinnitus or vertigo. Patients aged $<1$ and $>70$ years, patient requiring contrast study but were clinically unfit for contrast workup, pregnant women and patients who cannot give a valid consent were excluded from the study. Relevant clinical evaluation was carried out at the presentation. X-ray of mastoid was also reviewed if taken. After relevant examination and informed consent, C.T scan was performed as follows; The examination of patients was done using Brilliance 64 Philips CT scanner and after eliminating all the artefacts from the scanning area. It was done with $0.625 \mathrm{~mm}$ thick sections at slice gap of $0.625 \mathrm{~mm}$. $140 \mathrm{kV}$ and $300 \mathrm{mAs}$ were used as voltage and current. The cycle duration was 2 seconds. Scanning was done in axial plane. Scan plane was kept parallel to infraorbitomeatal line to prevent radiation to lens. Scanning was done so as to include temporal bone anteroposteriorly on both sides Entire petrous temporal bone was scanned anteroposteriorly in accordance with the topogram. Intravenous contrast was used only in cases that needed assessment of vascular lesions, soft tissue changes and breakdown of blood brain barrier, suspected either clinically or on plain scan. The images were reconstructed and visualized in special bone algorithm. Multiplanar reconstructions were done whenever required in sagittal and coronal planes. Documentation was done on $14 \mathrm{x}$ 17 " films. Images were magnified and recognized on separate sheets to enable comparison.

Follow up of patients was done for confirmation with operative and/or histopathological findings whenever possible. All the data thus obtained was recorded in a tabulated form and analysed.

\section{RESULTS}

The present study found that among 100 cases of temporal bone diseases (table 1), 61 cases were of infective etiology, out of which 16 were of chronic otomastoiditis, 4 were of

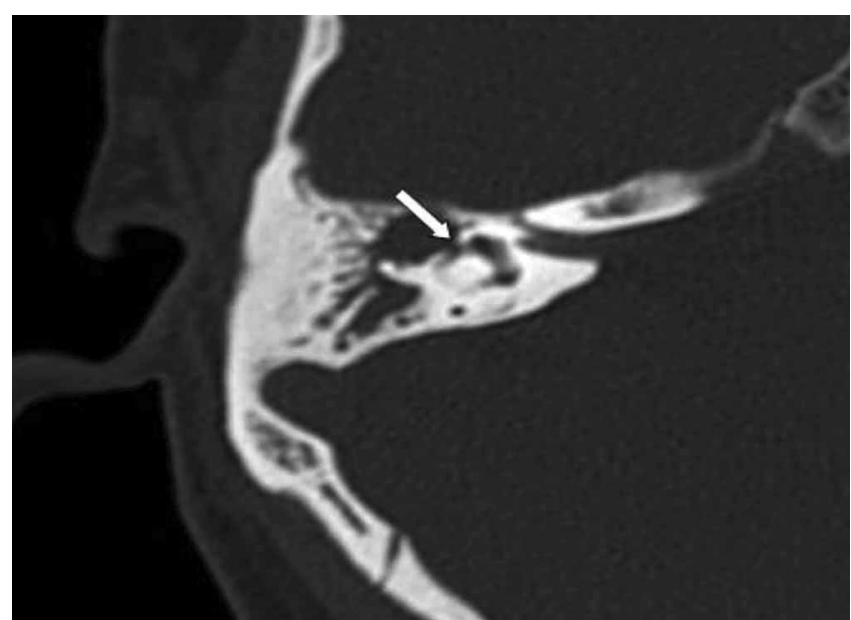

Figure-1: Cholesteatoma with labyrinthine fistula - Axial HRCT image right temporal bone demonstrates soft tissue in middle ear with erosion of bony wall of lateral semicircular canal (arrow).

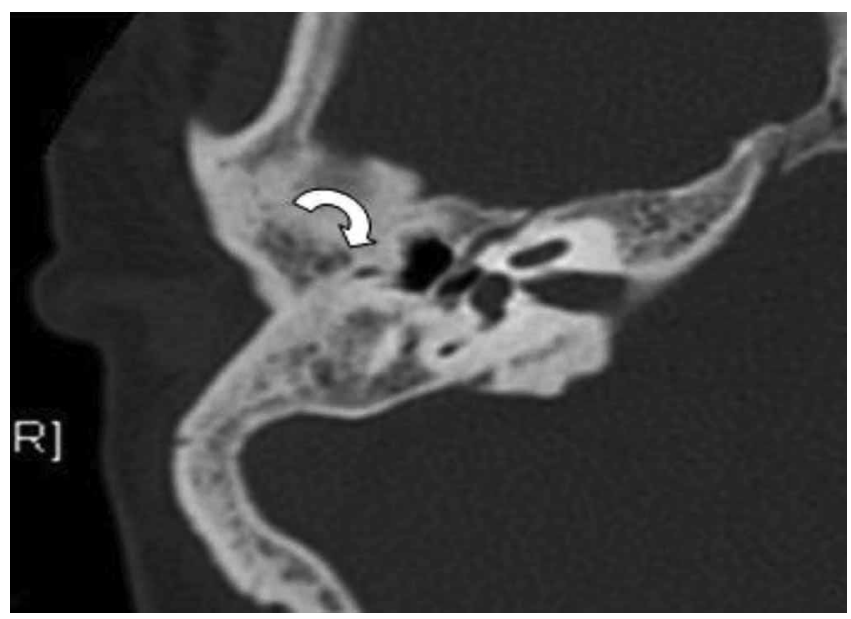

Figure-2: Microtia - Axial HRCT image right temporal bone in another case of microtia with small hypoplastic middle ear cavity, absent external auditory meatus (curved arrow), tympanic membrane and pinna. The innear ear structures appear normal.

\begin{tabular}{|c|c|c|c|}
\hline \multicolumn{2}{|l|}{ Etiology } & \multicolumn{2}{|c|}{ Number of cases } \\
\hline \multirow[t]{4}{*}{ Infective } & Chronic otomastoiditis & 16 & \multirow[t]{4}{*}{61} \\
\hline & Chronic mastoiditis & 4 & \\
\hline & Chronic otomastoiditis with cholesteatomas Formation & 38 & \\
\hline & Otitis externa & 3 & \\
\hline \multirow[t]{5}{*}{ Congenital } & Ossicular abnormalities & 1 & \multirow[t]{5}{*}{6} \\
\hline & Facial nerve involvement & 1 & \\
\hline & Microrotia & 2 & \\
\hline & Inner ear dysplasia & 1 & \\
\hline & Congenital cholesteatoma & 1 & \\
\hline \multirow[t]{3}{*}{ Traumatic (fracture cases) } & Transverse & 6 & \multirow[t]{3}{*}{22} \\
\hline & Longitudinal & 11 & \\
\hline & Mixed & 5 & \\
\hline \multicolumn{2}{|l|}{ Dysplasia } & \multicolumn{2}{|c|}{1} \\
\hline \multicolumn{2}{|l|}{ Neoplastic } & \multicolumn{2}{|c|}{4} \\
\hline \multicolumn{2}{|l|}{ Normal } & \multicolumn{2}{|c|}{6} \\
\hline \multicolumn{2}{|l|}{ Total } & \multicolumn{2}{|c|}{100} \\
\hline
\end{tabular}




\begin{tabular}{|l|c|}
\hline Structures Involved & No. of cases of cholesteatomas $(\mathbf{n = 3 9 )}$ \\
\hline Facial Nerve & 26 \\
\hline Ossicles & 23 \\
\hline Tegmen Tympani & 19 \\
\hline Sinus plate & 21 \\
\hline Intracranial structures & 10 \\
\hline Inner ear & 12 \\
\hline
\end{tabular}

Table-2: Distribution of cases according to structures Involved due to cholesteatomas

\begin{tabular}{|l|c|}
\hline HRCT finding & No. of cases $(\mathbf{n = 2 2})$ \\
\hline Hemotympanum & 11 \\
\hline Facial nerve involvement & 6 \\
\hline Labyrinthine involvement & 2 \\
\hline Ossicular involvement & 1 \\
\hline Intracranial involvement & 5 \\
\hline \multicolumn{2}{|c|}{ Table-3: HRCT findings in various trauma cases } \\
\hline
\end{tabular}

chronic mastoiditis, 38 were of chronic otomastoiditis with cholesteatomas formation and 3 were of otitis externa. Out of 100 cases, 6 were of congenital pathology, 22 were of traumatic, 1 was of dysplasia, 4 were of neoplastic and 6 were normal. Among congenital etiology 1 was of ossicular abnormalities, 1 was of facial nerve involvement, 2 were of microrotia, 1 was of inner ear dysplasia and 1 was of congenital cholesteatoma. Among 22 cases of traumatic etiology, 6 cases were of transverse type, 11 were of longitudinal and 5 were of mixed type.

Table 2 shows structures involved due to cholesteatomas, facial nerve was involved in 26 cases, ossicles in 23 cases, tegmen tympaniin 19 cases, sinus plate in 21 cases, intracranial structures in 10 cases and inner ear in 12 cases. Among trauma cases of temporal bone, HRCT showed hemotympanum involvement in 11 cases, facial nerve involvement in 6 cases, labyrinthine involvementin 2 cases, ossicular involvement in 1 case and intracranial involvement in 5 cases (table 3 ).

\section{DISCUSSION}

The present study found that among 100 cases of temporal bone diseases, 61 cases were of infective etiology, out of which 16 were of chronic otomastoiditis, 4 were of chronic mastoiditis, 38 were of chronic otomastoiditis with cholesteatomas formation and 3 were of otitis externa. Figure 1 shows image of cholesteatoma by high resolution computed tomography The role of $\mathrm{X}$-rays in evaluation of a cholesteatoma is very less. Minute alterations like erosion of ossicules, participation of concealed areas and destruction of facial canal and the LSSC are tremendously difficult to evaluate with X-ray. ${ }^{4}$ The aptitude of high-resolution CT to portray the station of structure of temporal bone presents a major advancement in defining pathology before surgical exploration in patients with cholesteatoma. ${ }^{5}$ The diagnosis of cholesteatoma is normally made on otological findings in situations where diagnosis is not clear. HRCT temporal bone may show a soft-tissue mass with distinguishing displacement of ossicles and erosion of bone. Cholesteatoma in hidden areas could be revealed by radiological evaluation even if it is not visualized clinically. High-resolution computed tomography scanning of the temporal bone is the imaging modalities of choice to evaluate the extension of cholesteatoma before surgery. ${ }^{6}$ Erosion occurs chiefly due to the substances released by mononuclear cells of inflammation and osteoclasts. An expanding cholesteatoma can erode the antrum and mastoid spaces, even additional structures like the bony facial canal, tegmen and the lateral semi-circular canal ${ }^{4}$ Out of 26 patients with facial canal involvement that were included in current study, 19 were confirmed by surgery. The results of the present study were in agreement with the study by Fuse $T$ et $\mathrm{al}^{7}$ who found that in $75 \%$ HRCT image based evaluation of facial nerve canal erosion coincided with surgical results. There were 97\% subjects HRCT results of semicircular canal fistula concurred with surgical results. As per the study by Thukral CL et a ${ }^{1}$ amongst 50 patients with clinically suspected temporal bone or ear pathologies found that the imaging results related to the surgical findings wherever possible. HRCT delivers a good sensitivity of approximately $80.65 \%$ in the documentation of variations to the ossicular chain regardless of the presence of soft tissue. Sreedhar $\mathrm{S}$ et $\mathrm{al}^{4}$ compared findings of HRCT scan of 25 patients clinically diagnosed to have CSOM attico-antral type of disease with the intraoperative findings. HRCT scan was found to have a high sensitivity for identification of the disease at most of the sites within the temporal bone except for the sinus tympani and the stapes region. Fritz $\mathrm{P}$ et $\mathrm{al}^{8}$ carried a radiological evaluation of temporal bone diseases and reported that highresolution CT allows for a clearer diagnosis amongst $80 \%$ of cases, conventional radiology enables the same amongst 63\%; which is 1.6-times more than the bone information recorded by high-resolution CT, clearly indicating superior features in imaging of cholesteatomas and inflammatory processes and for evaluation of bony destruction. High-resolution CT is the most delicate technique for imaging and classification of the fractures of temporal bone, like labyrinthine injury and ossicular chain damages.

Typical complications occurring from cholesteatoma like ossicular destruction, facial nerve canal, attical wall damage etc can be clearly demonstrated with this technique. As per the study by Koster $\mathrm{O}$ et $\mathrm{al}^{9}$ it was found that the degree of the soft tissue diseased process is clearly shown; however, the differentiation from associated inflammatory alterations is not possible.

In the present study, among cases of congenital etiology, 1 case was of ossicular abnormalities, 1 was of facial nerve involvement, 2 were of microrotia (figure 2), 1 was of inner ear dysplasia and 1 was of congenital cholesteatoma. These findings are in agreement with the findings of Meyer TE et $\mathrm{al}^{10}$ amongst 184 cases of congenital auricular dysplasia concluded that the extent of the auricular irregularities resembled to the severity of vicissitudes in the external auditory canal.

As regards trauma mechanisms and main complications of each type of temporal fracture, they may be summarized as follows: a) longitudinal fractures generally occur in cases of temporoparietal trauma, commonly affecting the extra labyrinthine segment, and presenting as main complications ossicular lesion and hemotympanum; b) on the other hand, 
transverse fractures generally occur in cases of frontal/ occipital traumas, with translabyrinthine involvement, whose main complication is facial nerve weakness. ${ }^{11}$ In the present study, among 22 cases of traumatic etiology, 6 cases were of transverse type, 11 were of longitudinal and 5 were of mixed type. HRCT showed Hemotympanum involvement in 11 cases, Facial nerve involvement in 6 cases, Labyrinthine involvementin 2 cases, Ossicular involvement in 1 case and Intracranial involvement in 5 cases. Twemlow $\mathrm{S}^{12}$ amongst 205 cases of temporal bone and found that it can precisely diagnose middle ear disease. He also contingent that it delivers efficient usage of resources with low risk to the subjects. The improved contrast and soft tissue definition possible with HRCT produced excellent images of soft tissue in air spaces. Therefore, HRCT seems to be the diagnostic modality of high-quality for cholesteatomas and different soft tissue lesions in ear. HRCT also clearly demonstrates various complications of cholesteatomas and provides a detailed preview of the temporal bone prior to surgery thus enabling the surgeon to operate without any surprises.

\section{CONCLUSION}

In patients with temporal bone trauma, HRCT accurately evaluates the fracture lines, ossicular disruptions and facial nerve canal injury. Hence it determines the management of trauma patients. A HRCT helps to explain the possible outcomes to the patient as well as assist the otologist to predict disease during the surgery

\section{REFERENCES}

1. Thukral CL, Singh A, Singh S, Sood AS, Singh K. Role of high resolution computed tomography in evaluation of pathologies of temporal bone. Journal of clinical and diagnostic research: JCDR. 2015;9(9):TC07.

2. Jyothi AC, Shrikrishna BH. Role of high resolution computed tomography in the evaluation of temporal bone lesions: our experience. International Journal of Otorhinolaryngology and Head and Neck Surgery. 2016;2(3):135-9.

3. Maqsood S, Dar IH, Bhat SA. Role of high resolution computed tomography in evaluation of temporal bone diseases. . IAIM 2018; 5(12): 15-22.

4. Sreedhar S, Pujary K, Agarwal AC, Balakrishnan R. Role of high-resolution computed tomography scan in the evaluation of cholesteatoma: A correlation of highresolution computed tomography with intra-operative findings. Indian J Otol 2015;21:103-6.

5. Sharma VK, Prajapati N, Sharma R, Iqbal Z, Dadoo $\mathrm{S}$. Radiological changes in anatomy of temporal bone in cases of unsafe chronic suppurative otitis media: A retrospective study. Indian J Otol 2017;23:176-9.

6. Bluestone $\mathrm{CD}$, Klein JO. Intracranial complications and sequelae of otitis media. In: Bluestone CD, editor. Paediatric Otolaryngology. 2nd ed., Vol. 1. Philadelphia: WB Saunders; 1990. p. 738-40.

7. Fuse T, Tada Y, Aoyagi M, Sugai Y. Ct detection of facial nerve canal dehiscence and semicircular canal fistula: comparison with surgical findings. J Comput Assist Tomogr 1996; 20(2): 221-4.

8. Fritz P, Rieden K, Lenarz T, Haels J, Winkel KZ.
Radiological evaluation of temporal bone disease: highresolution computed tomography versus conventional $\mathrm{X}$-ray diagnosis. The British journal of radiology. 1989;62(734):107-13.

9. Koster O, Strahler-Pohl HJ. Value of high resolution $\mathrm{CT}$ in diagnosing acquired cholesteatoma of middle ear. ROFO Fortschr Geb Roentgenstr Nuklearmed. 1985; 143(3):322-6.

10. Mayer TE, Brueckman H, Siegert R. HRCT of the temporal bone in dysplasia of the auricle and external auditory canal. Am J Neuroradiol., 1997; 18: 53- 7.

11. Costa AM, Gaiotti JO, Couto CL, Diniz RL, Motta EG, Gomes ND. Temporal bone trauma and complications: computed tomography findings. Radiologia Brasileira. 2013;46(2):101-5.

12. Twemlow S. Computerised tomography: its role in the assessment of ear disease. Radiogr Today, 1991; 57(648): 22- 6 .

\section{Source of Support: Nil; Conflict of Interest: None}

Submitted: 01-04-2019; Accepted: 17-04-2019; Published online: 03-06-2019 